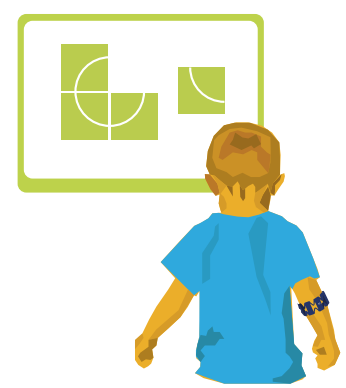

\title{
O USO DO DISPOSITIVO VESTÍVEL MYO EM JOGOS PARA REABILITAÇÃO DE CRIANÇAS COM DEFICIÊNCIA FÍSICA NOS MEMBROS SUPERIORES
}

\author{
APPLICATION OF GAMES FOR REHABILITATION OF CHILDREN WITH PHYSICAL DISABILITY
}

IN THE UPPER LIMBS

Flávia Gonçalves Fernandes

Professora do Departamento de Ciências da Computação da Universidade Federal de Goiás - Regional Catalão (UFG/RC). Doutoranda em Ciências Exatas e Tecnológicas pela UFG/RC. Mestre em Engenharia Biomédica pela Universidade Federal de Uberlândia - UFU. Bacharel em Engenharia da Computação pela Universidade de Uberaba - UNIUBE. flavia.fernandes92@gmail.com

Alexandre Cardoso

Professor da Faculdade de Engenharia Elétrica da Universidade Federal de Uberlândia (UFU). Doutor em Engenharia Elétrica pela UFU (2002). Mestre em Engenharia Elétrica pela UFU (1991). Bacharel em Engenharia Elétrica pela UFU (1987). alexandre@ufu.br

Renato de Aquino Lopes

Professor da Faculdade de Ciências da Computação da Universidade Federal de Uberlândia (UFU). Doutor em Engenharia Elétrica pela UFU (2016). Mestre em Ciências da Computação pela UFU (2003). Bacharel em Ciências da Computação pela UFU (1998). profrenatolopes@gmail.com.

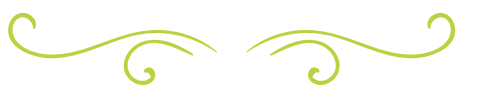

\section{RESUMO}

As características de imersão, envolvimento e motivação têm feito dos jogos sérios uma importante ferramenta utilizada na área médica. Entretanto, existem pessoas que, por alguma deficiência física, não conseguem ou não se sententem motivadas a jogar. Nessa perspectiva, este trabalho apresenta uma estratégia para suportar interação humano-computador de crianças com deficiência nos membros superiores por meio de dispositivo vestível, com o objetivo de melhorar o acesso aos jogos digitais para este público-alvo. Para o desenvolvimento deste trabalho, foi utilizado o dispositivo vestível Myo para controlar um jogo de quebra-cabeça como meio de prover a interação entre o indivíduo e o jogo. Neste contexto, o jogo é controlado pelos movimentos do membro superior do usuário, que apresenta a deficiência, por meio do Myo. Para validação da pesquisa, foi disponibilizado o jogo desenvolvido a indivíduos com deficiência física nos membros superiores, na faixa etária entre oito e quinze anos, da Associação de Assistência à Criança Deficiente (AACD). Logo, observou-se que os participantes da pesquisa conseguiram jogar utilizando o membro com deficiência com apoio do Myo e sentiram-se mais motivados a jogar. A longo prazo, espera-se contribuir na motivação dos pacientes, por meio das inovações tecnológicas, para que o processo de promoção da consciência corporal seja mais interativo, lúdico e atrativo. 
PALAVRAS-CHAVE: Deficiência Física, Dispositivos Vestíveis, Jogos Digitais, Membros Superiores.

\section{ABSTRACT}

The characteristic of immersion, involvement and motivation have made serious games an important tool to be used in the medical field. However, there are people that, for some physical disability, are not able to, or don't feel motivated to play. In this perspective, this work presents a strategy to support human-computer interactions for children with a disability in their upper limbs through a wearable device, with the objective of improving access to digital games for the target audience. For the development of this work, the wearable device Myo was used to control a puzzle game as a means of providing the interaction between the individual and the game. In this context, the game is controlled with the movement of the user's upper limb that presents the disability, through the Myo device. For the validation of this research, the game developed was made available for individuals presenting a disability in the upper limbs, from an age range between five and fifteen years old, of the Association of Assistance to the Disabled Child (AADC). Soon, it was noticed that the participants of the research soon could play while utilizing the deficient limb with Myo's support and felt more motivated to play. On the long run, it's expected to contribute to the motivation of patients through technological innovation, so that the process of body consciousness is made more interactive, attractive and playful.

KEYWORDS: Physical Disability, Wearables, Digital Games, Upper Limbs.

\section{INTRODUÇÃO}

De acordo com dados do censo do Instituto Brasileiro de Geografia Estatística
(IBGE) de 2015, há 12,7 milhões de pessoas portadoras de algum tipo de deficiência no Brasil, o que corresponde a cerca de 6,2\% da população. Grande parte dessas pessoas definem o tipo da deficiência como limitação física. Desse modo, é de grande relevância desenvolver melhorias para essa classe de pessoas, contribuindo, assim, para a inclusão social das mesmas [1].

Muitas vezes, pessoas com deficiência física ou mental são vítimas de preconceito e discriminação. Costumam não receber o mesmo tipo de tratamento e ter a liberdade de ir e vir prejudicada pelas más condições de vias de acesso público e privado. Porém, a Declaração Universal dos Direitos Humanos deixa claro que todas as pessoas devem ser tratadas fraternalmente, independente de deficiências. No caso específico do Brasil, a Constituição Federal define como meta a busca do bem-estar de todos, sem quaisquer tipos de discriminação. Da mesma maneira, o Código Penal brasileiro determina como passível de punição os atos criminosos e de desrespeito causados por fatores discriminatórios [2].

Pessoas com deficiência física nos membros superiores possuem limitações para realizar as atividades diárias [3]. Dessa forma, também podem ter dificuldades para utilizar dispositivos tecnológicos, como computadores, tablets, celulares em atividades que necessitam de duas mãos, como por exempos jogos digitais. Além disso, o longo tempo necessário para a promoção da consciência corporal, aceitação da deficiência e a pouca motivação gerada pelos métodos tradicionais são apontados como motivo de abandono do tratamento, caracterizando-se como uma das principais causas de falha terapêutica [4].

Outro problema encontrado por pessoas com deficiência física é a falta de recursos que possibilitem dar continuidade do tratamento domiciliar, com pouco ou nenhum monitoramento presencial de um terapeuta [5]. É importante lembrar ainda que geralmente as pessoas que nascem com 
malformação congênita de algum membro do corpo humano, também possuem outros problemas de saúde, que podem ser físicos (em outros membros), mentais, cardiovasculares, respiratórios, entre outros.

Por outro lado, existem trabalhos, tais como PhysioPlay [7] e MoVER - Movement in Virtual Environment for Rehabilitation [8], que comprovam a eficiência do uso de jogos na motivação de pacientes em continuar o tratamento de fisioterapia dos membros superiores. Ambos são jogos sérios que simulam movimentos fisioterapêuticos por meio de desafios para a realização de tarefas virtuais com o uso do corpo humano, demonstrando a possibilidade de tratamento remoto para a promoção da consciência corporal e o seu baixo custo.

Assim, a utilização do jogo digital pode tornar-se uma alternativa em proporcionar maior motivação nas brincadeiras por meio de desafios com técnicas virtuais, trabalhando conceitos que podem auxiliar na cognição, nos aspectos emocionais e físicos dos pacientes, no favorecimento dos movimentos do membro afetado, lazer, socialização e convivência com outras crianças. Além disso, a promoção da consciência corporal de forma virtual por meio de jogos visa simular situações reais; percebe-se que o uso dela melhora a funcionalidade dos membros acometidos e - leva a retomar as atividades nas áreas de desempenho ocupacional [6].

Além disso, a adaptação é importante para ampliar as potencialidades cognitivas das Pessoas com Necessidades Educacionais Especiais (PNEEs), o que é um dos grandes desafios do trabalho de inclusão no contexto escolar e social. Mas, mesmo com poucos recursos, é possível oferecer boas alternativas para atender às peculiaridades das pessoas com deficiência física adaptando materiais e equipamentos do cotidiano. $O$ uso deles permite que as pessoas com deficiência sejam capazes de se expressar, elaborar perguntas, resolver problemas e se tornar mais participativos, permitindo assim uma maior interação social com outras pessoas.

Neste contexto, o objetivo deste trabalho é desenvolver e avaliar um jogo adaptado para ser utilizado com o Myo, um dispositivo vestível que permite o controle de aplicativos por meio de reconhecimento de gestos, para prover uma melhor acessibilidade às pessoas que possuam algum tipo de deficiência nos membros superiores. Este trabalho é importante para incentivar o público-alvo a ampliar o seu acesso ao entretenimento digital, uma vez que jogos digitais podem ser importantes para o processo de promoção da consciência corporal das crianças e adolescentes com deficiência nos membros superiores. Também podem trazer outros benefícios, como auxiliar na aceitação da limitação motora, motivar os pacientes a utilizar com maior frequência o membro com deficiência, desenvolver e criar habilidades, despertar potenciais, conhecer novas tecnologias, melhorar a cognição, os aspectos emocionais e físicos, a socialização e o lazer.

Os trabalhos citados confirmam que a utilização dos jogos digitais ajuda a estimular os usuários a realizarem atividades do mundo real. Além disso, sabe-se que o uso de interfaces naturais é recente e estimulante, uma vez que são elementos naturais humanos, quase imperceptíveis quando o usuário está imerso na aplicação. Por isso, as Interfaces Naturais de Usuário (NUI) constituem o foco do presente trabalho, a saber: o dispositivo vestível Myo.

\section{DISPOSTIVOS VESTÍVEIS}

Dispositivos portáteis ou vestíveis são dispositivos eletrônicos que podem ser facilmente acoplados ao corpo do usuário. Eles possibilitam a presença da Realidade Virtual em diversas aplicações, visto que é uma tecnologia de interface avançada entre um usuário e um sistema computacional [9]. 
○ termo "computação vestível" ou "tecnologia vestível" se refere a uma nova abordagem de computação, redefinindo a interação humano-computador, onde os gadgets estão diretamente conectados com usuário. Os aparelhos vestíveis têm a intenção de tornar o usuário o mais "passivo" possível, focando no próprio ser humano e nas suas necessidades [9].

Comumente, neste tipo de tecnologia, existe uma constante interação entre o computador e o usuário, e alguns gadgets ligam e desligam automaticamente. Outra característica é a capacidade de multitarefa, pois não é necessário parar o que está fazendo para usar o dispositivo. Portanto, os dispositivos vestíveis podem ser uma extensão da mente e/ou do corpo do usuário [9].

Muitas questões são comuns aos dispositivos vestíveis, como computação móvel, inteligência artificial e computação ubíqua, incluindo também gerenciamento de energia, dissipação de calor, arquiteturas de software e redes [10].

Apesar de parecer um campo novo, o mercado de dispositivos vestíveis já existe há muitos anos na forma de aparelhos para medir batimentos cardíacos, monitorar corridas, entre outras funcionalidades, em sua maioria voltados para as áreas esportivas e de bem-estar. Com a evolução da tecnologia, a tendência é que esses dispositivos sejam introduzidos na medicina, ajudando, assim, a reduzir gastos e melhorar o tratamento de pacientes, possibilitando o monitoramento médico à distância.

No presente trabalho é proposto um jogo que, por meio da utilização de dispositivos vestíveis, procura auxiliar o tratamento de pessoas com deficiências motoras nos membros superiores. Nesse ponto, o dispositivo vestível utilizado no jogo proposto foi o Myo, o qual consiste em um bracelete de reconhecimento de gestos, que permite o controle de aplicativos e dispositivos sem a necessidade de interagir com nenhum outro periférico. $\bigcirc$ Myo utiliza os mesmos parâmetros de sinais mioelétricos que são utilizadas em próteses de braços. O mesmo é compatível com os mais populares sistemas operacionais e se comunica por Bluetooth, o que torna tal tecnologia propensa a ser rapidamente aceita e usada mundialmente. Além disso, não exige câmeras para rastrear os movimentos da mão ou braço e possuem baixo custo, em comparação com outros dispositivos vestíveis existentes no mercado [11].

O Myo é utilizado no antebraço do usuário. É necessário realizar uma calibração da braçadeira para cada usuário específico, pois cada um possui atividades e contrações musculares específicas. Após efetuada a sua calibração, o dispositivo possibilita controlar softwares e outras aplicações por meio de gestos e movimentos. Seu propósito é controlar computadores, telefones e outros dispositivos, enviando os dados capturados por ele via Bluetooth [11].

\section{TRABALHOS RELACIONADOS}

Dentre os trabalhos disponíveis na literatura, alguns deles apresentam desenvolvimento, conceitos e referências teóricas relacionados ao tema em questão. Assim, alguns trabalhos foram selecionados para serem correlados a este.

O Trabalho "Pediatric rehabilitation with the reachman's modular handle", apresenta os resultados de um estudo preliminar com uma criança com paralisia cerebral utilizando - ReHaptic Handle, um novo dispositivo robótico para a reabilitação pediátrica da função do membro superior. Jogos de computador interativos foram implementados para aumentar a participação dos participantes e engajamento, promovendo, assim, a recuperação motora. O pinçamento, com o indicador e o polegar, a supinação/pronação do antebraço, bem como a flexão/extensão do punho, foram treinados duas ou três vezes por semana durante quinze minutos cada. Observou-se um aumento da precisão e lisura do movimento de supinação/pronação do antebraço com o indivíduo, bem 
como uma redução na duração do movimento. Assim, é apresentada uma aplicação para crianças que tiveram paralisia cerebral, com a finalidade de auxiliá-las a retornar os movimentos de seus membros superiores normalmente. Este protótipo é importante, visto que a paralisia cerebral é uma doença neurológica não progressiva, causada por distúrbios do cérebro em desenvolvimento. A terapia física e ocupacional, se iniciada em tenra idade, pode ajudar a minimizar complicações, como contraturas conjuntas, e pode melhorar a amplitude de movimentos e a coordenação dos membros. Embora as formas atuais de terapia para crianças com paralisia cerebral sejam eficazes na minimização dos sintomas, muitas crianças acham que são chatas ou repetitivas [12].

○ Trabalho "Hand Therapist: a rehabilitation approach based on wearable technology and video gaming", trata-se de um sistema de reabilitação da mão, principalmente para pacientes vítimas de Acidente Vascular Cerebral (AVC), composto por: braçadeira Myo, luva robótica e a game engine Unity 3D. Esta abordagem apresenta uma solução que combina desempenho, baixo custo e motivação para terapia da mão. Dessa forma, a aplicação é uma forma de terapia de mão voltada para pacientes vítimas de AVC, que não possuem deficiência física, mas dificuldade de manuseio de objetos. Nesse sistema, o usuário faz diversos exercícios repetitivos para recuperar os movimentos da mão e, além do Myo, utilizam uma luva com sensores [13].

O Trabalho "Hand Posture and Gesture Recognition using Myo Armband and Spectral Collaborative Representation based Classification", propõe o uso da representação colaborativa baseada em Spectral Domain para reconhecer as posturas e gestos das gravações eletromiografia (EMG) adquiridos por um sensor recentemente introduzido: braçadeira Myo Thalmic Labs. A precisão de reconhecimento obtida para um conjunto de seis gestos e posturas é promissor, com uma precisão superior a 97\%, o que é um resultado eficiente na literatura relacionada. Os algoritmos são desenvolvidos para a criação de uma interface homem-máquina intuitiva para navegar em uma cadeira de rodas robótica. Este protótipo foi criado para pessoas que utilizam cadeira de rodas. Assim, o usuário movimenta a cadeira de rodas por meio de seus próprios gestos do braço em que está colocado o Myo. Neste caso, a deficiência das pessoas dá-se nos membros inferiores. Nestes dois projetos, o meio de interação poderia ser trocado para Kinect e joystick, respectivamente, o que provavelmente atingiria o mesmo resultado. Porém, no trabalho aqui apresentado, estas outras ferramentas tecnológicas não poderiam ser utilizadas, uma vez que as pessoas possuem deficiência física nos membros superiores e têm dificuldade em utilizar as ferramentas citadas [14].

Os trabalhos relacionados e apresentados nesta seção contribuem para a ratificação da relevância do uso de sistemas de interação natural para promoção da consciência corporal dos membros superiores ou interações alternativas. A relevância é ressaltada em ambientes relacionados com a área médica que necessitam de um processo de reprodução ou repetição de ações e/ou movimentos que produzem um cenário motivacional maior do que a metodologia tradicional.

Os trabalhos PhysioPlay [7] e MoVER [8], apresentados na seção de Introdução, apresentam controladores adaptados para pessoas com deficiência física nos membros superiores, similar a este trabalho. Porém, o presente trabalho utiliza um dispositivo vestível para adaptação controlado por gestos do próprio usuário, o que é algo mais prático e fácil de usar, além de ser uma tecnologia inovadora e atrativa para as pessoas.

Controladores de console típicos são equipados com vários botões e joysticks muitas vezes para ser operado ao mesmo tempo, tornando-se uma barreira real. 
Algumas soluções do-it-yourself existem adaptando controladores comerciais para necessidades especiais. Mas, desta forma, o controle do videogame é totalmente deixado para as pessoas com deficiência ou limitação física e, muitas vezes, ele ainda não é capaz de jogar o jogo com suas funcionalidades residuais. Além disso, tais soluções não são nem comercializáveis, sendo modificações não certificadas de um dispositivo comercial.

O trabalho [12], apresenta uma aplicação para crianças que tiveram paralisia cerebral, com a finalidade de auxiliá-las a retornar os movimentos de seus membros superiores normalmente. Este tipo de protótipo é importante, visto que a paralisia cerebral é uma doença neurológica não progressiva, causada por distúrbios do cérebro em desenvolvimento. A terapia física e ocupacional, se iniciada em tenra idade, pode ajudar a minimizar complicações, como contraturas conjuntas, e pode melhorar a amplitude de movimentos e a coordenação dos membros. Embora as formas atuais de terapia para crianças com paralisia cerebral sejam eficazes na minimização dos sintomas, muitas crianças acham que são chatas ou repetitivas.

Os trabalhos [13] e [14] apresentam pesquisas realizadas utilizando o dispositivo vestível Myo. Em [13], a aplicação é uma forma de terapia de mão voltada para pacientes vítimas de AVC, que não possuem deficiência física, mas dificuldade de manuseio de objetos. Nesse sistema, o usuário faz diversos exercícios repetitivos para recuperar os movimentos da mão e, além do Myo, utilizam uma luva com sensores. Em [14], o protótipo foi criado para pessoas que utilizam cadeira de rodas. Assim, o usuário movimenta a cadeira de rodas por meio de seus próprios gestos do braço em que está colocado o Myo. Neste caso, a deficiência das pessoas dá-se nos membros inferiores. Nestes dois projetos, o meio de interação poderia ser trocado para Kinect e joystick, respectivamente, o que provavelmente atingiria o mesmo resultado. Porém, no presente trabalho, estas outras ferramentas tecnológicas não poderiam ser utilizadas, uma vez que as pessoas possuem deficiência física nos membros superiores e têm dificuldade em utilizar as ferramentas citadas.

\section{MATERIAIS E MÉTODOS}

Primeiramente, na fase de Concepção, foi realizada uma pesquisa bibliográfica sobre jogos aplicados à área da saúde e em pessoas com deficiência, classificação de jogos e sua respectiva teoria do flow - estado mental de operação em que a pessoa está totalmente imersa no que está fazendo, caracterizado por um sentimento de total envolvimento e sucesso no processo da atividade -, tipos de deficiência física nos membros superiores, interfaces naturais, dispositivos vestíveis, dentre outros conceitos importantes para solucionar o seguinte problema: a dificuldade que pessoas com deficiência física nos membros superiores, principalmente crianças e adolescentes, tem ao utilizar dispositivos tecnológicos tradicionais, necessitando, muitas vezes, da ajuda de terceiros.

Após o levantamento bibliográfico e a seleção dos trabalhos relacionados a este, entrou-se em contato com a Associação de Assistência à Criança Deficiente (AACD)/ Unidade Uberlândia, para entender melhor o domínio do problema e, juntamente com a equipe da instituição - formada pela coordenadora, médicos, fisioterapeutas, terapeutas ocupacionais - foi escrito e submetido o projeto para avaliação do Comitê de Ética em Pesquisa (CEP) da Universidade Federal de Uberlândia por meio do sistema online chamado Plataforma Brasil. - projeto foi submetido na Plataforma Brasil com título "Jogos Sérios para Apoio à Reabilitação de Pacientes com Deficiência Física utilizando Interfaces Naturais" e CAAE: 55704316.3.0000.5152. 
A AACD foi escolhida como instituição coparticipante da pesquisa, visto que ela é a unidade mais próxima da Universidade Federal de Uberlândia, onde foi desenvolvida a pesquisa, que viabiliza o tratamento de promoção da consciência corporal do público-alvo dessa pesquisa: crianças e adolescentes com deficiência física nos membros superiores. Além disso, ela é a organização mais abrangente criada para receber o público-alvo desta pesquisa, atendendo pacientes de diversas cidades da região. A finalidade da AACD é proporcionar a melhoria da qualidade de vida e aquisição de maior autonomia e independência às pessoas com deficiência.

$\mathrm{Na}$ fase de Elaboração, utilizou-se o software Enterprise Architect [17] para modelagem da arquitetura do sistema e a construção de diagramas UML (Unified Modeling Language), de casos de uso, de classes, de atividades, análise de requisitos funcionais e não-funcionais da aplicação.

$\mathrm{Na}$ Figura 1, pode ser visualizada os requisitos funcionais, que contém informações sobre a interação entre o usuário e o jogo. Foi escolhido um jogo de quebra-cabeça porque este tipo de jogo pode auxiliar tanto na promoção da consciência corporal dos pacientes quanto nos aspectos cognitivos, uma vez que exercita o raciocínio lógico dos usuários, segundo informações obtidas com os profissionais da AACD.

Os requisitos não-funcionais definem propriedades e restrições do sistema. Exemplos: segurança, desempenho, espaço em disco. Eles podem ser do sistema todo ou de partes do sistema. Eles podem ser classificados em requisitos do produto (eficiência, confiabilidade, portabilidade, facilidade de uso, desempenho, espaço), organizacionais (entrega, implementação, padrões) e externos (reguladores, éticos, legais, privacidade e segurança) [16].

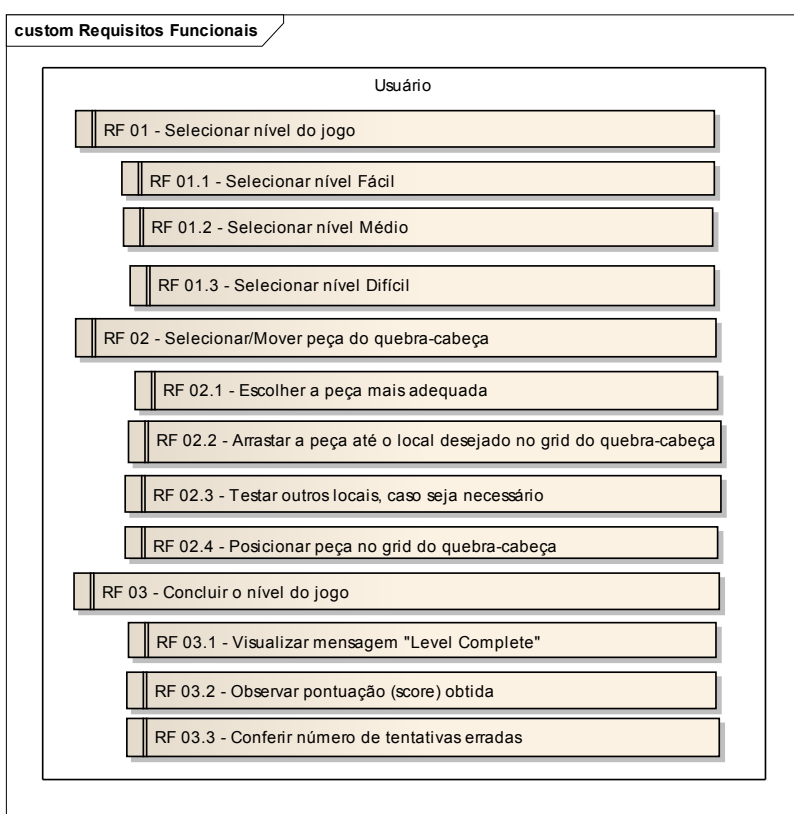

Figura 1 - Requisitos funcionais da aplicação.

Fonte: Próprio autor (2017).

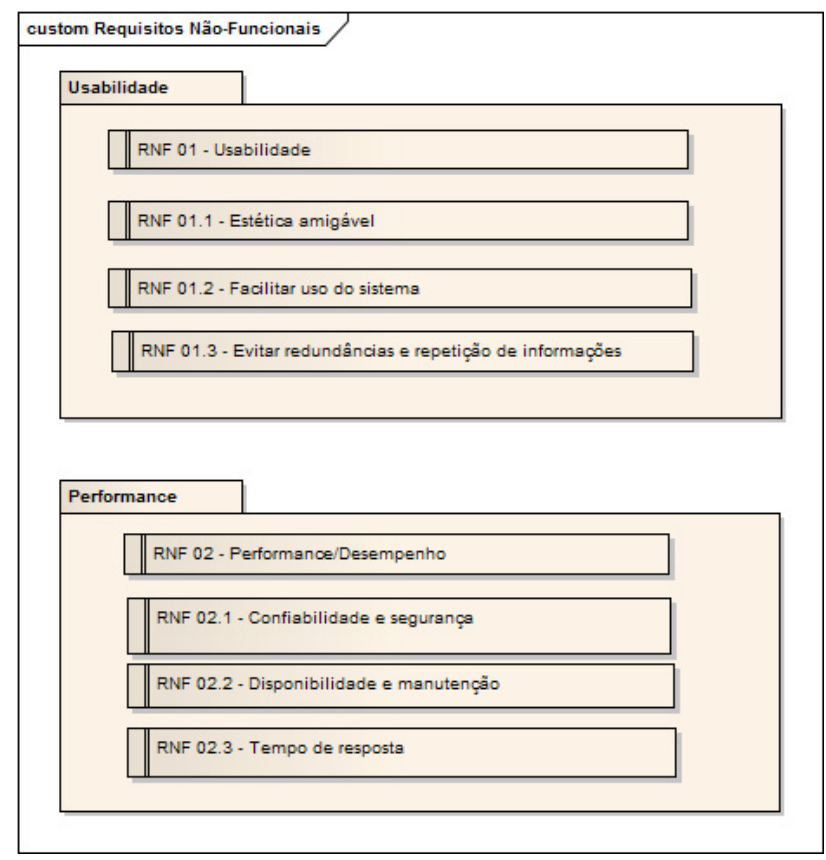

Figura 2 - Requisitos não-funcionais da aplicação.

Fonte: Próprio autor (2017).

Geralmente, os requisitos não-funcionais podem ser mais críticos que os requisitos funcionais, pois são de difícil verificação. Idealmente, os requisitos não-funcionais devem ser mensuráveis. Após a implementação, estes podem ser testados objetivamente [16].

A Figura 2 apresenta os requisitos não-funcionais, ou seja, contém informações sobre as características de qualidade que 
o sistema deve possuir e que estão relacionadas às suas funcionalidades. Buscou-se um jogo de gênero mais conhecido para facilitar o aprendizado dos comandos pelos usuários, além de procurar otimizar a usabilidade e a performance do sistema, uma vez que o Myo permite o cadastro limitado de gestos diferentes em uma mesma aplicação.

O diagrama de casos de uso é um diagrama que descreve do ponto de vista do usuário e as principais funcionalidades do sistema. Ele é representado por atores e casos de uso, onde o ator é o usuário do sistema ou um outro sistema computacional e um caso de uso define uma grande função do sistema computacional [16].

A Figura 3 mostra o diagrama de casos de uso do sistema desenvolvido, onde ilustra o usuário sendo o ator principal do sistema. O usuário pode selecionar o nível do jogo, mover as peças do quebra-cabeça até $\mathrm{o}$ grid até concluir o nível do jogo, e o seu controle ocorre por meio do dispositivo vestível Myo.

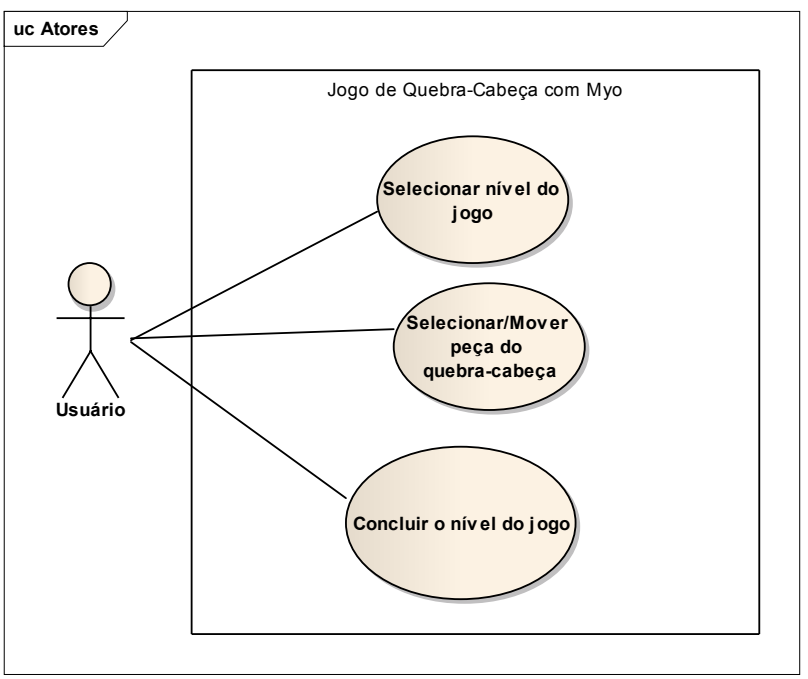

Figura 3 - Diagrama de casos de uso.

Fonte: Próprio autor (2017).

Na fase de Construção, foram utilizados o software Unity 3D [18] e a linguagem de programação C\# [19] para desenvolvimento do jogo de quebra-cabeça com três níveis de dificuldade. Posteriormente, alterou-se o Software Development Kit (SDK ou Kit de
Desenvolvimento de Software) do dispositivo vestível Myo, implementando-o no jogo. A game engine Unity 3D foi escolhida para ser utilizada neste trabalho, uma vez que ela oferece diversos recursos de computação gráfica necessários para implementação do projeto, além de possuir plugin de compatibilidade com o dispositivo vestível Myo. A linguagem de programação C\# também foi escolhida, por ser de fácil compatibilidade com o software Unity 3D.

Foi escolhido um jogo de quebra-cabeça porque este tipo de jogo pode auxiliar tanto na promoção da consciência corporal dos pacientes quanto nos aspectos cognitivos, uma vez que exercita o raciocínio lógico dos usuários, segundo informações obtidas com os profissionais da AACD.

Para o controle dos jogos, foi utilizado o dispositivo Myo, pois é um modelo comercializado livremente não só para pesquisadores, mas também para consumidores comuns que desejam utilizá-lo em jogos de computador ou para controle de outras aplicações. Por ser um método não-invasivo de eletromiografia, o dispositivo Myo não provoca efeitos colaterais ao participante da pesquisa, visto que é um acessório similar a um relógio ou pulseira, o qual não causa alergia, dor, irritação na pele, calosidades, nem qualquer outro dano ou prejuízo físico. Ele capta os gestos do participante e, em seguida, transmite para o computador, o qual reconhece os movimentos e executa as atividades durante a execução dos jogos. A construção do jogo e a escolha do gênero utilizado para esta pesquisa foram acompanhadas pela equipe da AACD, a qual tem maior experiência com os pacientes, público-alvo do trabalho.

Os símbolos apresentados na Figura 4 são os principais gestos realizados pelo usuário durante a execução de aplicações controladas pelo Myo, conforme padrão do dispositivo vestível. 


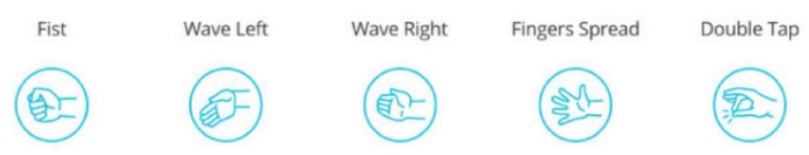

Figura 4 - Gestos executados pelo usuário.

Fonte: [11].

Nessa perspectiva, foram realizados vários testes para entender o funcionamento do bracelete e dos plugins disponibilizados para download, com a finalidade de conhecer as várias possibilidades do que se pode fazer com o Myo.

No jogo de quebra-cabeça apresentado, o gesto "Double Tap" é utilizado para iniciar o jogo. Os gestos "Wave Left" e "Wave Right" são utilizados para selecionar as peças do quebra-cabeça para a esquerda e para a direita, respectivamente. Para mover as peças até o grid, utiliza-se o gesto "Fist", e para encaixar as peças do quebra-cabeça no grid, utiliza-se o gesto "Fingers Spread".

Após esses procedimentos, pode-se desbloquear o software, colocar o Myo no braço do usuário, efetuar a calibração do dispositivo e usar os movimentos do braço da pessoa ao invés de mouse e teclado. Dessa forma, foram substituídos os comandos que utilizam o mouse e teclado no jogo por gestos do usuário, para que o sistema seja usado com o dispositivo vestível Myo.

\section{UTILIZAÇÃO DO JOGO}

A Figura 5 apresenta a Interface Gráfica do Usuário (GUI) principal do "Quebracabeça com Myo". No menu inicial, há três opções de níveis do jogo: Iniciante, Intermediário e Avançado.

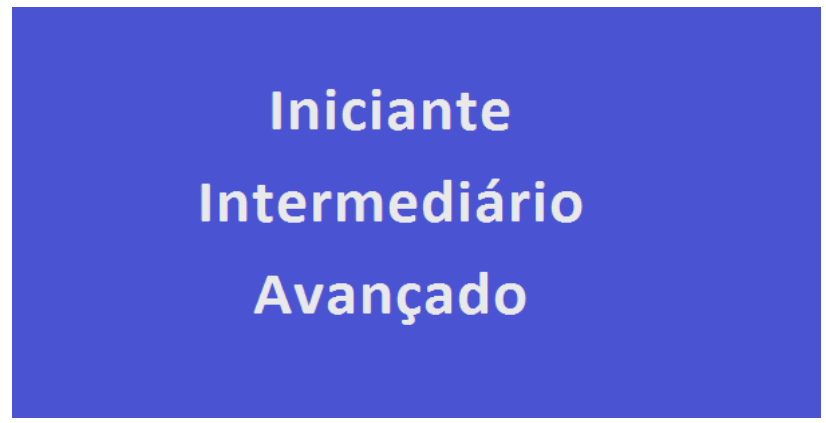

Figura 5 - Menu inicial do jogo.

Fonte: Próprio autor (2017).
Ao selecionar o nível "Iniciante", é exibido o jogo de quebra-cabeça $2 \times 2$, ou seja, com quatro peças, conforme pode ser visto na Figura 6.

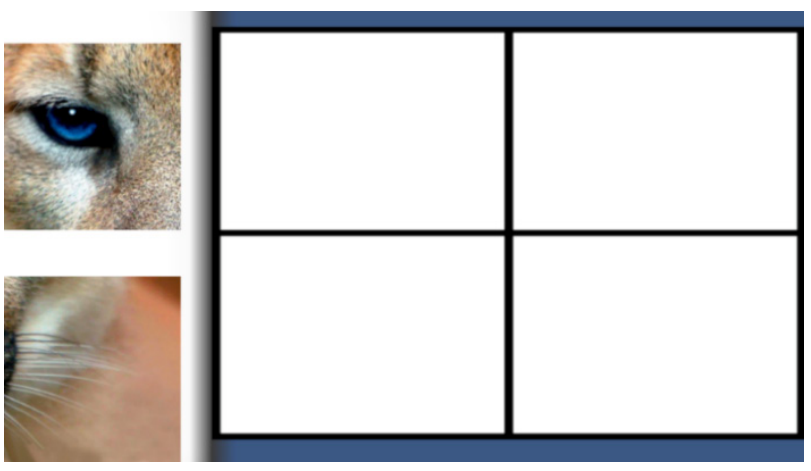

Figura 6 - Tela inicial do Nível Iniciante.

Fonte: Próprio autor (2017).

As peças do jogo ficam do lado esquerdo da tela. Para arrastar as peças para o grid do quebra-cabeça, é preciso fazer gestos com o braço que está utilizando o dispositivo vestível Myo até concluir o nível atual do jogo.

Após a conclusão do nível do quebra-cabeça, é exibida a mensagem "Nível Concluído" juntamente com a pontuação e o número de tentativas erradas do usuário durante o jogo, conforme pode ser observado na Figura 7. Há também a opção de retornar ao menu inicial para selecionar outro nível do jogo.

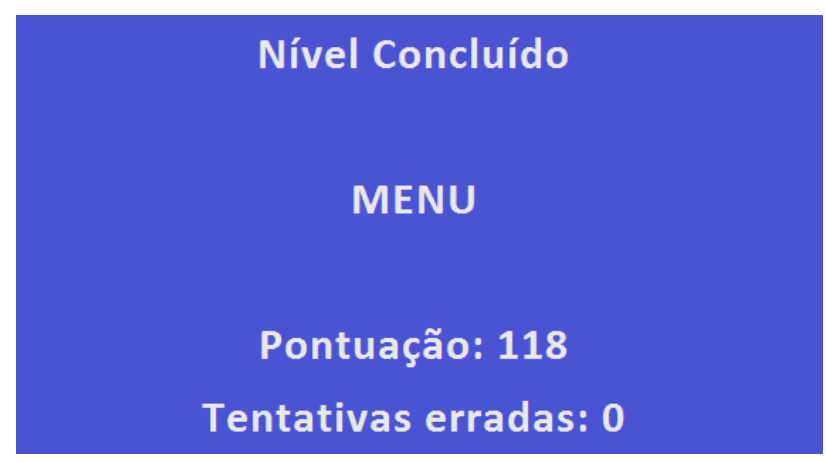

Figura 7- Nível do jogo concluído.

Fonte: Próprio autor (2017).

Ao escolher o nível "Intermediário", é apresentado o jogo de quebra-cabeça $3 x$ 3 , isto é, com nove peças. A Figura 8 apresenta a Tela inicial do Nível Intermediário, em que o jogo está em resolução, uma vez que algumas peças já foram inseridas no grid do jogo. 


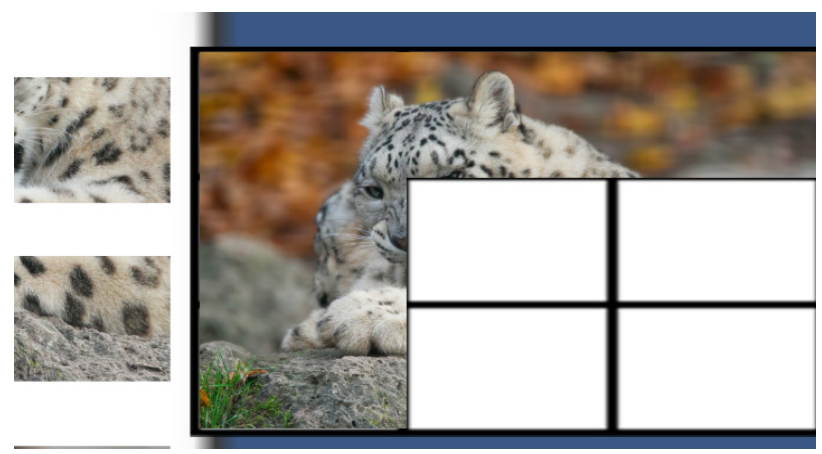

Figura 8 - Nível Intermediário do jogo em resolução.

Fonte: Próprio autor (2017).

A Figura 9 apresenta o nível "Avançado" do jogo concluído. Nele, o jogo de quebra-cabeça possui grid $4 \times 4$, isto é, com dezesseis peças.

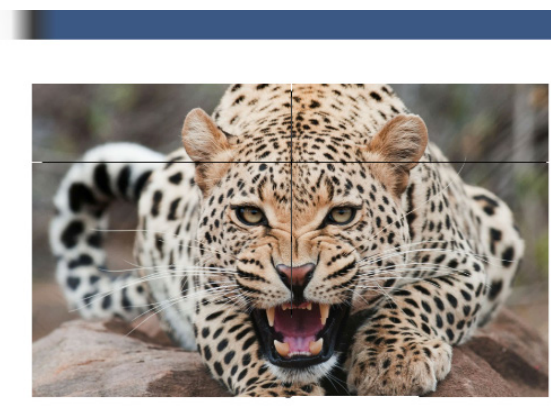

Figura 9 - Nível Avançado concluído.

Fonte: Próprio autor (2017).

\section{CONCEPÇÃO E APLICAÇÃO DOS TESTES}

Primeiramente, a AACD fez um levantamento do público-alvo para a pesquisa: crianças e adolescentes com faixa etária entre oito e quinze anos que possuem deficiência física nos membros superiores.

Neste levantamento, foram encontradas 44 pacientes que já frequentaram a instituição com este tipo de deficiência. Em seguida, foram feitas ligações telefônicas para entrar em contato com as famílias desses pacientes e explicar sobre a pesquisa. Dos 44 pacientes, 24 manifestaram interesse em participar da pesquisa. Os outros 20 pacientes não participaram pelos seguintes motivos: alguns não foram encontrados, pois o telefone cadastrado no sistema da instituição não existe mais; outros mudaram de cidade e/ou estado; outros moram em cidades vizinhas, mas acham difícil a locomoção até a cidade de Uberlândia para participação da pesquisa; outros alegaram que seus filhos já ganharam alta da $A A C D$, que convivem bem com a deficiência física no cotidiano e não tem interesse em participar da pesquisa; outros ainda disseram que os filhos não queriam participar da pesquisa.

Desse modo, foi preparada uma sala da AACD para recepcionar os pacientes e suas famílias para a realização dos testes com o jogo controlado pelo dispositivo vestível Myo. Nas datas e horários marcados, apareceram dez participantes da pesquisa, onde foi apresentado o projeto em forma de slides para explicar melhor a sua finalidade, e vídeo demonstrativo de funcionamento do jogo. Posteriormente, foram entregues o Termo de Consentimento Livre e Esclarecido (TCLE) aos pais e o Termo de Assentimento para as crianças e adolescentes, e foram solucionadas dúvidas sobre o projeto de pesquisa. Após a leitura dos TCLEs, os mesmos foram assinados.

Em seguida, foi preenchido o questionário sobre avaliação do perfil do indivíduo com os dados pessoais do participante da pesquisa (criança ou adolescente), o qual pode ser visualizado no Anexo I. Ele aborda questões sócio demográficas, e foi elaborado a partir de um questionário de uso interno da AACD.

As 10 crianças que participaram da pesquisa possuem deficiência física congênita (desde o nascimento), ocasionada por malformação durante a gestação: 5 crianças possuíam agenesia de mão direita (CID 071.3 - Ausência congênita de mão e de dedos) e outras 5 possuíam hipoplasia de falanges (CID 071.8 - Outros defeitos de redução do membro superior). As crianças possuem outras deficiências também, podendo ser físicas (nos membros inferiores), mentais ou cardiovasculares. Os testes foram realizados com: uma criança de 8 anos, uma criança de 9 anos, duas crianças de 10 anos, duas crianças de 11 anos, duas crianças de 12 anos e 
duas crianças de 13 anos. Dessas crianças, 6 indivíduos eram do gênero feminino e 4 eram do gênero masculino.

As outras perguntas do questionário de avaliação do perfil dos indivíduos participantes da pesquisa permitiram identificar que os gêneros de jogos preferidos das crianças são: jogos de aventura, raciocínio e criatividade. Além disso, verificou-se que as crianças estão no ensino fundamental, a maioria está no ano escolar adequado para sua idade. Porém, algumas já tiveram reprovações e estão um pouco atrasadas, pois possuem problemas de déficit de atenção, hiperatividade e dificuldade de aprendizagem.

As crianças também possuem limitações para a realização das atividades cotidianas que necessitam de ambas as mãos, visto que as 10 crianças que participaram da pesquisa possuem deficiência no membro superior direito. Dessa forma, elas são canhotas e procuram fazer a maioria das atividades com a mão esquerda.

Também se questionou sobre o grau de experiência das crianças com tecnologia, computadores, tablets e celulares. As respostas obtidas indicaram que os participantes da pesquisa usam dispositivos tecnológicos de modo intensivo, apesar de possuírem deficiência no membro superior. Porém, os pais disseram que seus filhos gostam de utilizar esses aparelhos apenas em casa, com a família. Em ambientes externos, elas têm vergonha de mostrar a sua limitação motora no membro superior para pessoas desconhecidas, devido ao receio de preconceito e rejeição.

Além disso, foi perguntado às crianças referente ao grau de experiência das crianças com jogos digitais e videogame. Nele, observa-se que há um uso moderado de jogos. Segundo os pais, as crianças não conseguem jogar a maioria dos jogos digitais sozinhas devido à deficiência no membro superior direito, e ficam frustradas por não terem autonomia ao realizar esta prática. Então, os pais alegaram que não autorizam seus filhos a jogar muito para evitar esse tipo de situação, o que pode acarretar comportamento de baixa autoestima das crianças e redução do convívio social.

Então, foi colocado o bracelete Myo no braço do participante da pesquisa para que os comandos do jogo sejam controlados pelos gestos e movimentos da criança ou adolescente.

Algumas crianças tiveram o comportamento igual ao jogar com ambos os braços. Porém, outras apresentaram maior dificuldade de controlar o jogo com o braço que possui a deficiência. Isso pode ocorrer devido a vários fatores, dentre eles: pouco uso do membro com deficiência e anomalias musculares próprias da deficiência.

Após a execução do jogo, foi aplicado ao participante da pesquisa um questionário sobre a avaliação da utilização do jogo mediada pelo dispositivo vestível Myo. $O$ atendimento a cada participante da pesquisa foi realizado de maneira individual. Todos os procedimentos foram acompanhados pelos pais e por uma terapeuta ocupacional que trabalha na AACD.

O questionário para avaliação da utilização de jogos mediada pelo dispositivo Myo foi elaborado a partir de um questionário para avaliação de jogos educacionais, proposto por [15], apresentado no Anexo II. Ele foi escolhido porque aborda diversas características importantes sobre a jogabilidade com crianças, entre elas: motivação, atenção, relevância, confiança, satisfação, experiência do usuário, imersão, desafio, habilidade, competência, conforto, interesse, divertimento, aprendizado e conhecimento. Dessa forma, o questionário foi adaptado, reduzindo-o para 20 perguntas. Além das questões já existentes no questionário de [15], foram incluídas outras perguntas sobre o Myo, com a finalidade de abordá-lo melhor nos testes e investigar quais são os seus impactos na pesquisa. Além disso, este questionário foi feito utilizando a linguagem em primeira pessoa adequada 
para a faixa etária e também expressões faciais para facilitar o entendimento das crianças quando forem responder o mesmo, conforme pode ser visto no Anexo III.

\section{ANÁLISE DOS RESULTADOS}

A seguir, são apresentados os resultados obtidos a partir da aplicação do questionário de avaliação do jogo de quebra-cabeça por intermédio do dispositivo vestível Myo:

Para a $1^{\text {a }}$ pergunta do questionário "Eu já conhecia o dispositivo Myo?" , todos os participantes da pesquisa responderam "Nada", o que corresponde a 100\% da amostra. Assim, pode-se observar que nenhum dos participantes da pesquisa conhecia o Myo, ou seja, o bracelete foi uma novidade para as crianças envolvidas nos testes e para os seus respectivos pais.

Para a $2^{a}$ pergunta do questionário "Eu já utilizei o Myo anteriormente?", todos os participantes da pesquisa responderam "Nada", o que corresponde a 100\% da amostra. Dessa forma, verifica-se que nenhum dos participantes da pesquisa já utilizou o dispositivo vestível, isto é, esse foi o primeiro contato dos usuários com o Myo.

Na Figura 10, é mostrado o resultado referente às respostas para a $3^{a}$ pergunta do questionário "Foi fácil aprender a utilizar o Myo para jogar?". Então, observa-se que a aprendizagem para utilização do Myo foi moderada, visto que as respostas apresentadas foram variadas. Isso ocorreu porque algumas crianças têm déficit de atenção e dificuldade de aprendizagem, correlacionadas à deficiência física no membro superior, o que, consequentemente, também pode prejudicar a adaptação ao novo método de jogar.
3. Foi fácil aprender a utilizar o Myo para jogar?

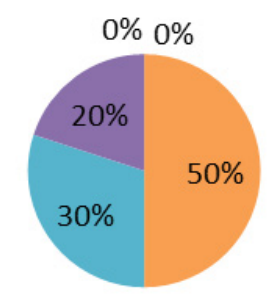

Muitíssimo $\square$ Muito $\mathbf{m a i s}$ ou Menos Pouco $\mathbf{n}$ Nada

Figura 10 - Facilidade de adaptação ao Myo

Fonte: Próprio autor (2017).

Para a $4^{a}$ pergunta do questionário "Foi confortável utilizar o Myo para jogar?", todos os participantes da pesquisa responderam "Muitíssimo", o que corresponde a 100\% da amostra. Dessa forma, pode-se observar que todos os participantes da pesquisa apreciaram o conforto do dispositivo vestível, uma vez que ele não machuca nem provoca alergias, é similar a um bracelete ou pulseira.

Para a $5^{a}$ pergunta do questionário "Gostei de controlar o jogo utilizando o Myo?", todos os participantes responderam "Muitíssimo", o que corresponde a $100 \%$ da amostra. Assim, verifica-se que todos os participantes da pesquisa gostaram de controlar o jogo utilizando o Myo, pois a possibilidade de usá-lo para controlar os comandos do jogo foi uma grande novidade para as crianças.

Para a 6 a pergunta do questionário "O Myo atendeu às minhas expectativas?", todos os participantes responderam "Muitíssimo", o que corresponde a $100 \%$ da amostra. Desse modo, percebe-se que o dispositivo atendeu às expectativas de todas as crianças que participaram da pesquisa. Elas ficaram muito empolgadas quando o projeto foi apresentado a elas em forma de slides e vídeo demonstrativo. Elas também ficaram muito felizes e surpresas ao aprender a jogar e ao conseguir controlar o jogo com seus próprios gestos.

Para a $7^{a}$ pergunta do questionário "Eu achei o jogo legal e interessante?", todos os 
participantes responderam "Muitíssimo", o que corresponde a 100\% da amostra. Assim, observa-se que todos os participantes acharam o jogo legal e interessante, e sentiram-se motivadas a executar os comandos do jogo utilizando seus próprios gestos, a acertar as peças de encaixe no quebra-cabeça e concluir o jogo.

Para a $8^{a}$ pergunta do questionário "Foi fácil manter a atenção no jogo?", todos os participantes responderam "Muitíssimo", o que corresponde a $100 \%$ da amostra. Dessa maneira, verifica-se que todos os participantes da pesquisa consideraram fácil manter a atenção no jogo. Primeiramente, porque as crianças estavam interessadas em realizar os movimentos corretos com o membro superior para concluir o jogo e atingir maior pontuação. Além disso, o quebra-cabeça é um jogo que exige raciocínio e atenção para ser jogado. Outro aspecto importante observado foi que, apesar do uso do novo dispositivo para as crianças, já que elas não conheciam o Myo, e da sua utilização pelo membro com deficiência, elas mantiveram a atenção no jogo, o interesse em jogar e concluir os níveis do quebra-cabeça, ou seja, é uma indicação de que elas estiveram em flow, estado mental de operação em que a pessoa está imersa no que está fazendo, caracterizado por um sentimento de total envolvimento e sucesso no processo da atividade.

$\mathrm{Na}$ Figura 11, é mostrado o resultado referente às respostas para a $9^{a}$ pergunta do questionário "As atividades do jogo foram fáceis de entender?". Assim, percebe-se que os participantes da pesquisa consideraram as atividades do jogo de fácil entendimento, visto que o quebra-cabeça é um tipo de jogo conhecido por eles, e as imagens a serem montadas são de animais, algo de conhecimento deles também.
9. As atividades do jogo foram fáceis de entender?

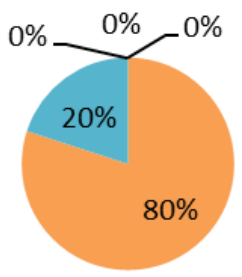

- Muitíssimo Muito $\square$ Mais ou Menos Pouco $\mathbf{n}$ Nada

Figura 11 - Facilidade de entendimento do jogo.

Fonte: Próprio autor (2017).

A Figura 12 apresenta o gráfico referente às respostas para a $10^{a}$ pergunta do questionário "Foi fácil aprender os comandos para execução do jogo?". Dessa forma, observa-se que aprender os comandos para execução do jogo foi algo considerado moderado, uma vez que as crianças não conheciam o dispositivo Myo nem outras tecnologias que controlam jogos por meio de gestos. Além disso, as crianças possuem vergonha, limitação motora e pouca frequência de uso do membro superior utilizado para jogar.

\section{Foi fácil aprender os} comandos para execução do jogo?

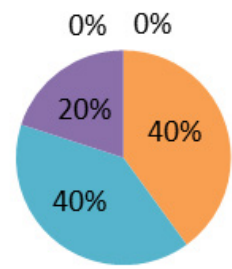

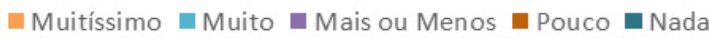

Figura 12 - Facilidade em aprender os comandos do jogo.

Fonte: Próprio autor (2017).

Na Figura 13, é exibido o resultado referente às respostas para a $11^{a}$ pergunta do questionário "Eu consegui executar todos os comandos do jogo?". Então, percebe-se que todos os participantes do jogo conseguiram executar todos os comandos 
do jogo, apesar da novidade e de, inicialmente, não quererem utilizar o membro com deficiência para jogar. Porém, depois demonstraram habilidade e satisfação ao jogar o quebra-cabeça com o Myo.

\section{Eu consegui executar todos} os comandos do jogo?

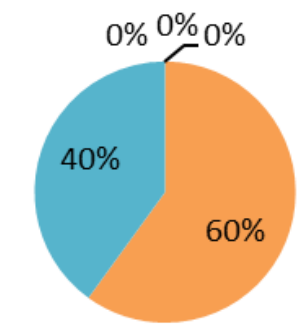

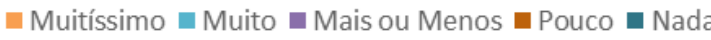

Figura 13 - Habilidade com o jogo.

Fonte: Próprio autor (2017).

Para a $12^{a}$ pergunta do questionário "Eu me esforcei para ter bons resultados no jogo?", todos os participantes responderam "Muitíssimo", o que corresponde a 100\% da amostra. Desse modo, pode-se observar que os participantes da pesquisa se esforçaram para ter bons resultados no jogo, pois estavam interessados e motivados a jogar e concluir o jogo com maior pontuação.

$\mathrm{Na}$ Figura 14, mostra-se o resultado referente às respostas para a $13^{a}$ pergunta do questionário "A velocidade de execução do jogo foi rápida?". Assim, verifica-se que a velocidade de execução do jogo foi mediana, uma vez que algumas crianças demoraram um pouco para aprender os comandos do jogo por meio de gestos. Elas também estavam com dificuldades devido ao pouco uso do membro com deficiência e à limitação motora do mesmo.

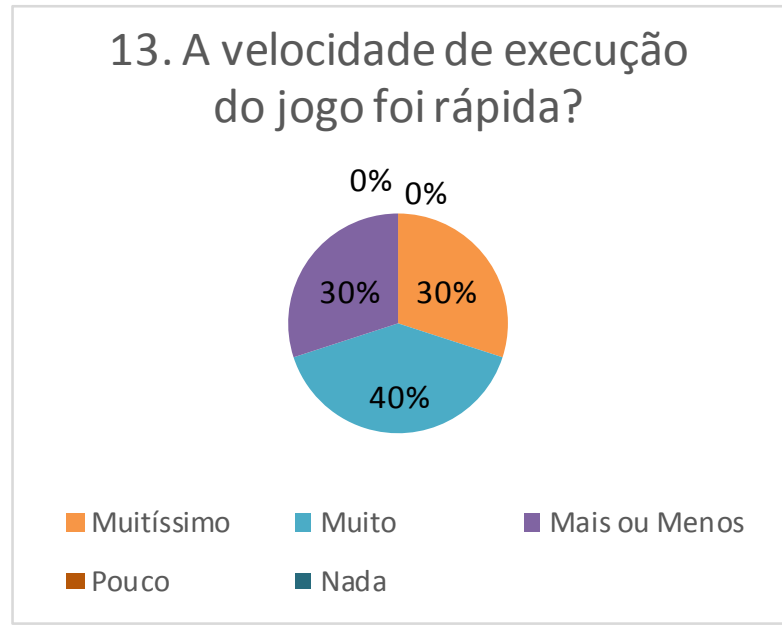

Figura 14 - Velocidade de execução do jogo.

Fonte: Próprio autor (2017).

Para a $14^{a}$ pergunta do questionário "Eu me diverti durante o jogo?", todos os participantes responderam "Muitíssimo", o que corresponde a $100 \%$ da amostra. Dessa forma, percebe-se que todos os participantes se divertiram durante o jogo. Era nítida a felicidade deles por conseguir controlar o jogo com seu próprio membro com limitação, emitiam uma sensação de surpresa e sentiam-se úteis, o que pode ampliar a sua autonomia e a aceitação da deficiência.

Para a $15^{a}$ pergunta do questionário "Eu fiquei envolvido no jogo?", todos os participantes responderam "Muitíssimo", o que corresponde a 100\% da amostra. Então, observa-se que os participantes da pesquisa ficaram envolvidos com o jogo, sentiram-se imersos no jogo de quebra-cabeça, em flow, isto é, o balanceamento correto entre o desafio inerente à atividade e à habilidade do jogador em superá-lo. Esses fatos ocorreram devido à familiaridade com as imagens do jogo e também à praticidade do dispositivo Myo.

A Figura 15 apresenta o gráfico referente às respostas para a $16^{\mathrm{a}}$ pergunta do questionário "Eu me senti ansioso ou entediado durante o jogo?". Dessa forma, visualiza-se que a maioria dos participantes não se sentiram ansiosos ou entediados durante o jogo, visto que o dispositivo Myo e a possibilidade do controle do jogo por meio dele 
foram novidades atrativas e interessantes para os participantes da pesquisa.

\section{Eu me senti ansioso ou} entediado durante o jogo?

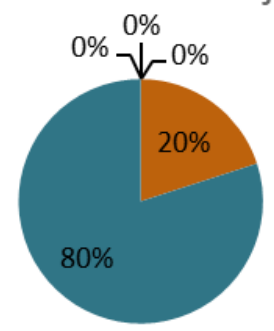

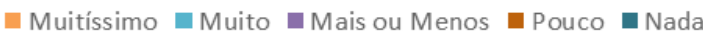

Figura 15 - Ansiedade ou tédio durante o jogo.

Fonte: Próprio autor (2017).

Para a $17^{a}$ pergunta do questionário "Eu me senti estimulado a aprender com o jogo?", todos os participantes responderam "Muitíssimo", o que corresponde a 100\% da amostra. Assim, verifica-se que todos os participantes da pesquisa se sentiram estimulados a aprender com o jogo, treinaram suas habilidades e competências, superaram os desafios e medos, com a finalidade de concluir o jogo.

A Figura 16 mostra o gráfico referente às respostas para a $18^{a}$ pergunta do questionário "Eu consegui concluir o jogo?". Dessa forma, percebe-se os participantes da pesquisa conseguiram concluir o jogo. As crianças que selecionaram a opção "Muito" nesta questão apresentaram dificuldades para conseguir concluir o nível "Difícil" do jogo, necessitando de ajuda dos pesquisadores para dar dicas, devido ao seu déficit de atenção e dificuldade de concentração e aprendizagem.

\section{Eu consegui concluir o} jogo?

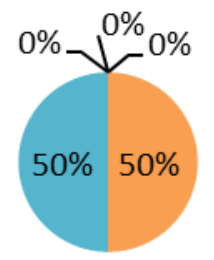

$$
\begin{array}{ll}
\text { Muitíssimo } & \text { Muito } \\
\text { - Mouco } & \text { Mada ou Menos }
\end{array}
$$

Figura 16 - Conclusão do jogo.

$$
\text { Fonte: Próprio autor (2017). }
$$

Na Figura 17, exibe-se o resultado referente às respostas para a $19^{a}$ pergunta do questionário "O jogo atendeu às minhas expectativas?". Assim, observa-se que o jogo atendeu às expectativas dos participantes da pesquisa. Eles jogaram com muito esforço e dedicação para aprender os comandos utilizando o Myo e concluir o quebra-cabeça.

19. $O$ jogo atendeu às minhas expectativas?

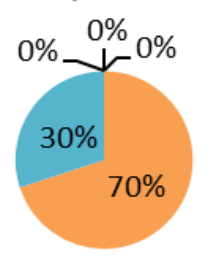

Muitíssimo $\square$ Muito $\square$ Mais ou Menos $\square$ Pouco $\mathbf{n}$ Nada

Figura 17 - Expectativas do jogo.

Fonte: Próprio autor (2017).

Para a $20^{a}$ pergunta do questionário "Eu gostaria de jogar este jogo novamente?", todos os participantes responderam "Muitíssimo", o que corresponde a 100\% da amostra. Dessa forma, vê-se que todos os participantes da pesquisa ficaram satisfeitos e gostariam de jogar o quebra-cabeça utilizando o Myo novamente. Elas encontraram uma nova possibilidade para jogar com autonomia, utilizando seu membro com deficiência, e sem a necessidade de depender 
de outras pessoas para ajudarem-nas a jogar. Logo, demonstra a importância e a relevância da pesquisa na vida dos participantes.

\section{CONCLUSÕES E TRABALHOS FUTUROS}

Os resultados provenientes dos testes realizados mostram que jogos mediados pelo Myo pode ser uma boa alternativa para prover acessibilidade para pessoas com deficiência nos membros superiores. Tornar os jogos digitais mais acessíveis para esse público é relevante pois pode proporcionar maior acesso ao entretenimento digital, além de maior desenvolvimento e utilização do membro, podendo também auxiliar no processo de promoção da consciência corporal. Dessa forma, os benefícios, discutidos na literatura, que o ato de jogar pode proporcionar as pessoas torna-se mais acessível para as pessoas.

A escolha do jogo de quebra cabeça se mostrou adequada para os testes pois os participantes demonstraram, por meio de suas respostas, que o jogo foi bom, estimulante e atendeu as expectativas. Foi importante a escolha de um jogo simples em virtude da faixa etária dos participantes, bem como possíveis problemas neurológios apresentados pelos mesmos. Assim, eles puderam empreender uma maior carga congnitva na utilização do Myo e não na aprendizagem do jogo, uma vez que o dispositivo vestível era uma novidade para todos os participantes.

A utilização do Myo foi bem aceita. Os participantes se sentiram confortáveis e conseguiram interagir com o jogo alcançando os objeivos propostos pelo mesmo. Apesar de terem apresentado uma dificuldade moderada na utilização do Myo, este fato não interferiu na motivação e no envolvimento dos participantes com o jogo. Eles relataram que tiveram uma experiência divertida ao jogar. Dessa forma, percebe-se que o Myo pode ser utilizado como um dispositivo para melhorar a acessibilidade de possoas com deficiência física nos membros superiores aos jogos digitais. Tornando os jogos mais acessíveis espera-se uma maior utilização dos jogos digitais pelo público alvo desta pesquisa. Assim, eles poderão usufruir dos benefícios da utilização dos jogos apresentados na literatura.

As principais dificuldades encontradas na realização deste trabalho foram a demora para aprovação do projeto pelo Comitê de Ética em Pesquisa (cerca de sete meses) e o reconhecimento dos movimentos pelo dispositivo vestível Myo, devido à sua complexidade e à diversidade de variáveis envolvidas neste processo.

Portanto, verifica-se que o objetivo proposto no início deste trabalho foi alcançado, uma vez que a utilização de jogos mediados pelo dispositivo vestível Myo se mostrou eficiente no uso de jogos digitais para pessoas com deficiência física nos membros superiores, proporcionando maior autonomia e acessibilidade ao entretenimento digital.

Assim, a longo prazo, a estratégia apresentada pode auxiliar na aceitação da limitação motora, motivar os pacientes a utilizar com maior frequência o membro com deficiência, desenvolver e criar habilidades, despertar potenciais, conhecer novas tecnologias, melhorar o processo de consciência corporal, os aspectos emocionais, físicos e cognitivos, a socialização e o lazer.

Logo, diante dos resultados referentes aos testes efetuados com pacientes e os questionários respondidos por eles, pode-se afirmar que é uma modalidade terapêutica inovadora para a promoção da consciência corporal, e também pode incentivar na criação de novos objetos de estudo e sistemas na área médica.

Como trabalhos futuros, pretende-se prosseguir com a seleção, desenvolvimento e adaptação de mais jogos com a finalidade de melhorar o incentivo ao entretenimento digital para crianças e adolescentes com deficiência física nos membros superiores. 
Também acompanhar os impactos que a utilização do jogo a longo prazo pode acarretar para a promoção da consciência corporal dos indivíduos, do ponto de vista físico-motor e cognitivo.

Além disso, espera-se testar o jogo de quebra-cabeça para uso com o Myo com mais pacientes com deficiência física nos membros superiores, ampliar a faixa etária de aplicação do protótipo, e auxiliar a AACD na inauguração e manutenção da sala de Reabilitação Virtual na instituição em Uberlândia.

Também almeja-se realizar testes com pacientes que possuam deficiência física nos dois membros superiores para avaliar os resultados. E, posteriormente, nestes casos, verificar a possibilidade de utilizar dois dispositivos vestíveis (um para cada membro), podendo ampliar a pesquisa para uma estratégia de análise multimodal.

Ainda, deseja-se pesquisar dispositivos vestíveis para adaptar mais jogos para outros membros do corpo humano. Se possível, encontrar estratégias genéricas para utilização de jogos para todos os tipos de deficiência com a finalidade de promover a consciência corporal dos pacientes que se encontram nesta categoria. E também realizar o desenvolvimento de um módulo de supervisão da aplicação, no qual o profissional habilitado poderia visualizar gráficos para acompanhar a evolução de determinando paciente, e também comparar os resultados obtidos por diferentes pacientes na execução do jogo. 


\section{REFERÊNCIAS}

IBGE. Instituto Brasileiro de Geografia e Estatística. 2015. Disponível em: $\quad<$ http://www.ibge.gov.br/home/estatistica/populacao/estimativa2015/>. Acesso em: 15 ago. 2016.

GUIA de direitos. Discriminação com Deficientes. 2016. Disponível em: <http://www.guiadedireitos.org/index.php?option=com_content\&view=article\&id=1040\&ltemid=264>. Acesso em: 20 ago. 2016.

KOUROUPETROGLOU, G.. Disability Informatics and Web Accessibility for Motor Limitations. IGI Global, 2013.

DIAS, R.S.; SAMPAIO, I.L.A.; TADDEO, L.S. Fisioterapia: A Introdução do Lúdico no processo de reabilitação de pacientes em tratamento fisioterapêutico. In: VIII Brazilian Symposium on Games and Digital Entertainment. 4. Rio de Janeiro-RJ, 2009.

BOTELLA, C. et al. Treating cockroach phobia with augmented reality. Behavior Therapy, v.41. n. 3, p. 401-413, 2010.

GRANDE, A. A. B.; GALVÃO, F. R. O.; GONDIM, L. C. A.. Reabilitação virtual através do videogame: relato de caso no tratamento de um paciente com lesão alta dos nervos mediano e ulnar. Revista Acta Fisiátrica, Rio Grande do Norte, v. 18, n. 3, p. 157-162, 2011.

SANTOS, J. V. S.; CARVALHO, L. C.; BRESSAN, P. A.. Physioplay: um exergame para reabilitação física aplicando a interatividade do Kinect como biofeedback visual. In: IX Workshop de Realidade Virtual e Aumentada - WRVA, Paranavaí, 2012.

SOUSA JUNIOR, V. D. et al. MoVER: Serious Game aplicado à reabilitação motora usando sensor de movimento Kinect. In: Congresso da Sociedade Brasileira de Computação - CSBC, Maceió, 2013.

MANN, S.. Computação Wearable. In: Encyclopedia of Interação Humano-Computador. Aarhus, Dinamarca: A Fundação InteractionDesign.org, 2012.

MICROSOFT. Vestir-se para o Futuro: Microsoft Duo rompe com Wearable Conceito da tecnologia, Microsoft News Center, 2013.

MYO. Thalmic Labs: Myo Gesture Control Armband. 2016. Disponível em: <https://www.thalmic.com/myo/>. Acesso em: 30 mar. 2016.

TONG, L. Z. et al. Pediatric rehabilitation with the reachMAN's modular handle. Procedings IEEE Eng. Med. Biol. Soc., 2015; 2015:3933-6. doi: 10.1109/EMBC.2015.7319254. 
LIPOVSKÝ, R.; FERREIRA H. A.. Hand Therapist: a rehabilitation approach based on wearable technology and video gaming. Portuguese BioEngineering Meeting. 4. Porto: Portugal, 2015.

BOYALI, A.; HASHIMOTO, N.; MATSUMOTO, O.. Hand Posture and Gesture Recognition using Myo Armband and Spectral Collaborative Representation based Classification. In: IEEE 4th Global Conference on Consumer Electronics - GCCE, 2015.

SAVI, R. et al. Proposta de um modelo de avaliação de jogos educacionais. Novas Tecnologias na Educação, v. 8, n. 3, dezembro, 2010.

PRESSMAN, R. S.. Engenharia de software. 8 ed. Pearson Education do Brasil, São Paulo, 2016.

ENTERPRISE Architect. 2016. Disponível em: <http://sparxsystems. com/products/ea/>. Acesso em: 20 ago. 2016.

UNITY 3D. 2016. Disponível em: <https://unity3d.com/pt>. Acesso em: 20 ago. 2016.

MACHADO, L. S. et al. Realidade virtual para saúde no Brasil: conceitos, desafios e oportunidades. Revista Brasileira de Engenharia Biomédica. v. 27, n. 4, p. 243-258, 2011. 


\section{ANEXO I \\ Questionário para Avaliação do Perfil do Indivíduo}

\section{1 - Dados do Indivíduo:}

1.1. Sexo: ( ) masculino ( ) feminino

1.2. Data de nascimento: - Idade:

1.3. Tipo de deficiência:

( ) Amelia

( ) Agenesia

( ) Focomelia ( ) Hemimelia

( ) Hipoplasia

( ) Outra:

\subsection{Deficiência:}

( ) congênita (desde o nascimento);

( ) adquirida (após o nascimento).

1.5. O que ocasionou a deficiência?

1.6. Há quanto tempo possui a deficiência:

\section{Perfil do Indivíduo:}

2.1. Qual o seu grau de experiência com o uso de tecnologia, computadores, tablets, celulares?

Muitíssimo ( ) Muito ( ) Mais ou menos ( ) Pouco ( ) Nada ( )

Caso NÃO tenha utilizado aparelhos tecnológicos, justifique o motivo.

Falta de interesse ( ) Falta de oportunidade ( ) Outro:

2.2. Qual o seu grau de experiência com uso de jogos digitais ou video games?

Muitíssimo ( ) Muito ( ) Mais ou menos ( ) Pouco ( ) Nada ( )

Caso NÃO tenha utilizado jogos ou vídeo games, justifique o motivo.

Falta de interesse ( ) Falta de oportunidade ( ) Outro:

2.3. Qual o seu gênero de jogos preferido?

\subsection{Você está em qual ano escolar?}

2.5. Possui alguma limitação de deslocamento, função ou desempenho para realização de atividades cotidianas? 


\section{ANEXO II}

\section{Quadro 1 - Questionário para avaliação de jogos educacionais}

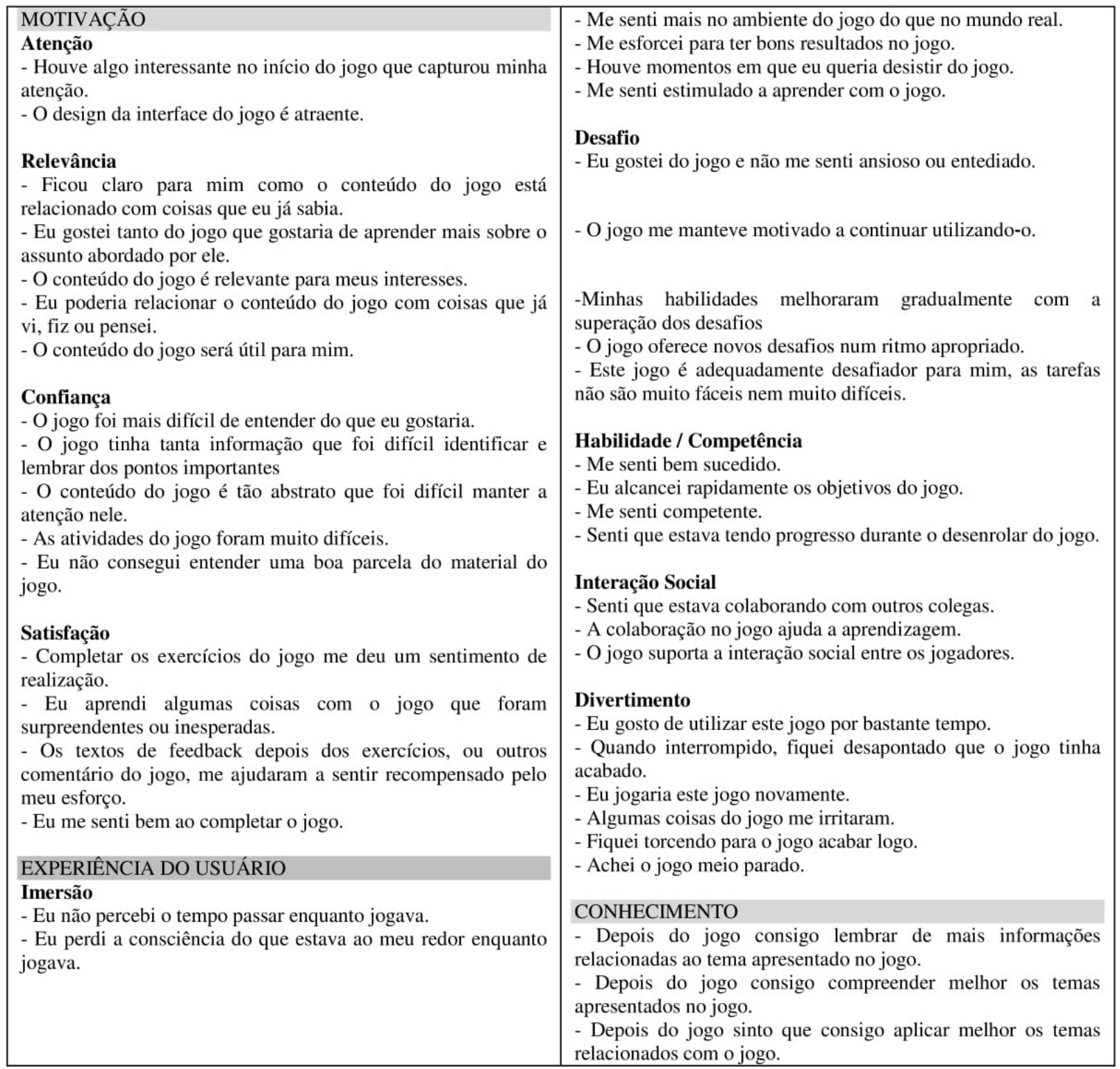




\section{ANEXO III}

\section{Questionário para Avaliação da Utilização de Jogos Mediada pelo Dispositivo Myo}

1. Eu já conhecia o dispositivo Myo?

2. Eu já utilizei o Myo anteriormente?

3. Foi fácil aprender a utilizar o Myo para jogar?

4. Foi confortável utilizar o Myo para jogar?

5. Gostei de controlar o jogo utilizando o Myo?

6. O Myo atendeu às minhas expectativas?

7. Eu achei o jogo legal e interessante?

8. Foi fácil manter a atenção no jogo?

9. As atividades do jogo foram fáceis de entender?

10. Foi fácil aprender os comandos para execução do jogo?

11. Eu consegui executar todos os comandos do jogo?

12. Eu me esforcei para ter bons resultados no jogo?

13. A velocidade de execução do jogo foi rápida?

14. Eu me diverti durante o jogo?

15. Eu fiquei envolvido no jogo?

16. Eu me senti ansioso ou entediado durante o jogo?

17. Eu me senti estimulado a aprender com o jogo?

18. Eu consegui concluir o jogo?

19. $O$ jogo atendeu às minhas expectativas?

20. Eu gostaria de jogar este jogo novamente?

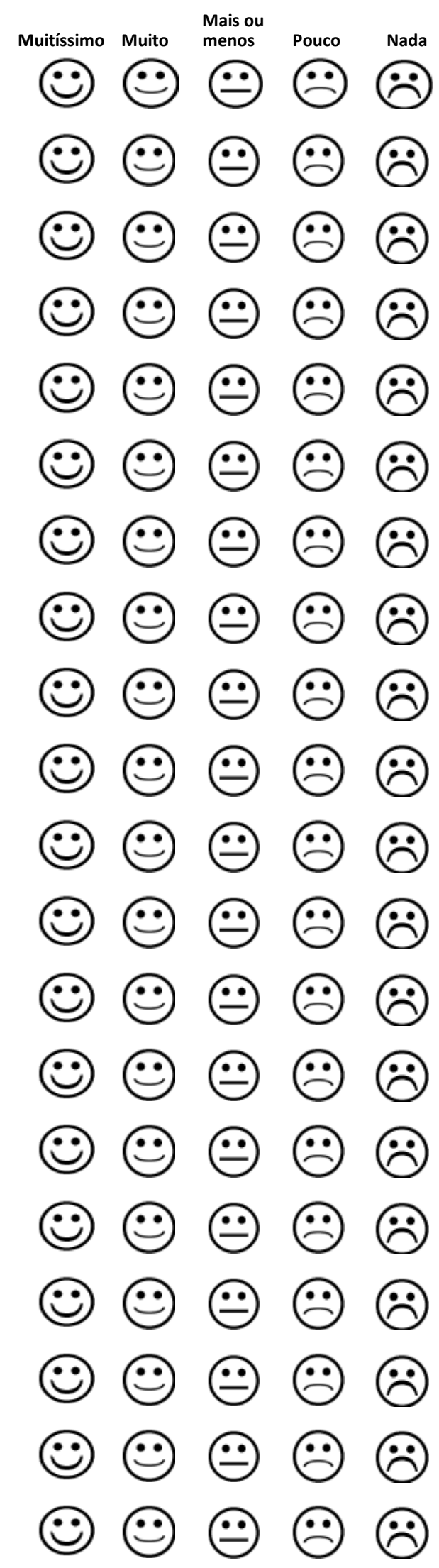

